\title{
Editorial Note: Review Papers for Journal of Risk and Financial Management (JRFM)
}

\author{
Michael McAleer 1,2,3,4,5 \\ 1 Department of Finance, College of Management, Asia University, Taichung 41354, Taiwan; \\ michael.mcaleer@gmail.com \\ 2 Discipline of Business Analytics, University of Sydney Business School, Sydney, NSW 2006, Australia \\ 3 Econometric Institute, Erasmus School of Economics, Erasmus University Rotterdam, 3062 PA Rotterdam, \\ The Netherlands \\ 4 Department of Economic Analysis and ICAE, Complutense University of Madrid, 28223 Madrid, Spain \\ 5 Institute of Advanced Sciences, Yokohama National University, Yokohama 240-8501, Japan
}

Received: 24 April 2018; Accepted: 24 April 2018; Published: 25 April 2018

\begin{abstract}
The Journal of Risk and Financial Management (JRFM) was inaugurated in 2008 and has continued publishing successfully with Volume 11 in 2018. Since the journal was established, JRFM has published in excess of 110 topical and interesting theoretical and empirical papers in financial economics, financial econometrics, banking, finance, mathematical finance, statistical finance, accounting, decision sciences, information management, tourism economics and finance, international rankings of journals in financial economics, and bibliometric rankings of journals in cognate disciplines. Papers published in the journal range from novel technical and theoretical papers to innovative empirical contributions. The journal wishes to encourage critical review papers on topical subjects in any of the topics mentioned above in financial economics and in cognate disciplines.
\end{abstract}

The Journal of Risk and Financial Management (JRFM) was inaugurated in 2008 and has continued publishing successfully with Volume 11 in 2018.

Since the journal was established, JRFM has published in excess of 110 topical and interesting theoretical and empirical papers in financial economics, financial econometrics, banking, finance, mathematical finance, statistical finance, accounting, decision sciences, information management, tourism economics and finance, international rankings of journals in financial economics, and bibliometric rankings of journals in cognate disciplines.

Topical issues have covered, among many others, risk measures, basis risk, default risk, competing risk, downside risk, upside risk, equity risk, risk calibration, optimal hedging, quadratic hedging, life insurance, reinsurance, financial distress, mergers and acquisitions, stock market integration, forecasting dispersion, stock market crashes, corporate risk and creditworthiness, corporate governance, sensitivity analysis, conserving capital, capital regulation, gammas and deltas, spot and futures markets, financial derivatives, exchange traded funds, generating latent variables, arbitrage, trading strategies, international diversification, domestic diversification, publicly traded companies, Bayesian models, option pricing, asymmetry and leverage, implied volatility, local volatility, conditional volatility, stochastic volatility, realized volatility, long memory volatility, collapsing bubbles, mean reversion, quantile regressions, factor analysis, fossil fuels, fertilizers, technical efficiency, nonparametric analysis, entropy, oscillation, default models, executive compensation, portfolio optimization, stochastic dominance, higher-order stochastic dominance, equilibria, stochastic control, finite mixture models, interest rate derivatives, exchange rates, collateralized derivative trading, Value-at-Risk, conditional Value-at-Risk, expected shortfall, cross listings, Basel Accord, heavy tails, skewness, higher moments, network analysis, inflation, speculation, expectations, stress testing, credit default swaps, vine copulas, property portfolios, social capital, structured finance, credit 
scoring, fuzzy support vectors, board structures, firm performance, mortgages, neural networks, integration, fractional integration, cointegration, high frequency, ultrahigh frequency, cloud migration, insolvency, bankruptcies, crypto-currencies, safety evaluation, trade openness, emerging economies, sustainability, foreclosures, experimental evidence, innovations, simulations, text mining, learning, big data, computational science, marketing, management, psychology, contagion, and natural disasters.

Papers published in the journal range from novel technical and theoretical papers to innovative empirical contributions, all of which are welcome as contributions to the journal.

The journal wishes to encourage critical review papers on topical subjects on any of the topics mentioned above in financial economics and in cognate disciplines.

The Editor-in-Chief and editorial staff of JRFM at MDPI look forward to working with potential authors of review papers, for which the editorial process would be handled efficiently and in a timely manner.

Acknowledgments: For financial support, the author wishes to thank the Australian Research Council and the Ministry of Science and Technology (MOST), Taiwan.

Conflicts of Interest: The author declares no conflict of interest.

(C) 2018 by the author. Licensee MDPI, Basel, Switzerland. This article is an open access article distributed under the terms and conditions of the Creative Commons Attribution (CC BY) license (http:/ / creativecommons.org/licenses/by/4.0/). 